\title{
Forced Expiratory Volume in 3 Seconds
}

National Cancer Institute

\section{Source}

National Cancer Institute. Forced Expiratory Volume in 3 Seconds. NCI Thesaurus. Code C132453.

The volume exhaled during the first three seconds of a forced expiratory maneuver that is started from the level of total lung capacity. 